\title{
Copper homeostasis at the host vibrio interface: lessons from intracellular vibrio transcriptomics
}

\author{
Vanhove Audrey ${ }^{1}$, Rubio Tristan ${ }^{1}$, Nguyen An N. 2, Lemire Astrid ${ }^{3,4}$, Roche David 5, 6 , Nicod Julie ${ }^{1}$, \\ Vergnes Agnes ${ }^{1}$, Poirier Aurore 1, Disconzi Elena 2, Bachere Evelyne 1, Le Roux Frederique 3, 4 , \\ Jacq Annick, Charriere Guillaume ${ }^{1}$, Destoumieux-Garzon Delphine 1, *
}

${ }^{1}$ Univ Montpellier, Univ Perpignan, CNRS, IFREMER,IHPE,UMR 5244, Via Domitia, F-34095

Montpellier, France.

2 Univ Paris 11, CNRS, CEA, I2BC, F-91405 Orsay, France.

3 IFREMER, Unite Physiol Fonct Organismes Marins, CS 10070, F-29280 Plouzane, France.

4 Univ Paris 06, Sorbonne Univ, Integrat Biol Marine Models, Stn Biol Roscoff,UMR 8227,CS

90074,CNRS, F-29688 Roscoff, France.

${ }^{5}$ Commissariat Energie Atom \& Energies Alternat CEA, DSV, Inst Genom, Genoscope, F-91057 Evry, France.

${ }^{6}$ CNRS, Lab Anal Bioinformat Genom \& Metab LABGeM, UMR 8030, F-91057 Evry, France.

* Corresponding author : Delphine Destoumieux-Garzon, email address : ddestoum@ifremer.fr

\begin{abstract}
:
Recent studies revealed that several vibrio species have evolved the capacity to survive inside host cells. However, it is still often ignored if intracellular stages are required for pathogenicity. Virulence of Vibrio tasmaniensis LGP32, a strain pathogenic for Crassostrea gigas oysters, depends on entry into hemocytes, the oyster immune cells. We investigated here the mechanisms of LGP32 intracellular survival and their consequences on the host-pathogen interaction. Entry and survival inside hemocytes were required for LGP32-driven cytolysis of hemocytes, both in vivo and in vitro. LGP32 intracellular stages showed a profound boost in metabolic activity and a major transcription of antioxidant and copper detoxification genes, as revealed by RNA sequencing. LGP32 isogenic mutants showed that resistance to oxidative stress and copper efflux are two main functions required for vibrio intracellular stages and cytotoxicity to hemocytes. Copper efflux was also essential for host colonization and virulence in vivo. Altogether, our results identify copper resistance as a major mechanism to resist killing by phagocytes, induce cytolysis of immune cells and colonize oysters. Selection of such resistance traits could arise from vibrio interactions with copper-rich environmental niches including marine invertebrates, which favour the emergence of pathogenic vibrios resistant to intraphagosomal killing across animal species.
\end{abstract}




\section{Introduction}

Vibrios have long been considered extracellular organisms. However, an increasing number of studies show that some vibrio strains have evolved cell invasive properties. The capacity to survive in host cells was reported for vibrio strains pathogenic for humans. Examples include Vibrio cholerae, which survives in mouse cell lines (Duperthuy et al., 2010), and V. parahaemolyticus, which disrupts the intestinal epithelium (Ritchie et al., 2012) and can also invade and replicate in human HeLa cell line (Zhang et al., 2012; de Souza Santos and Orth, 2014). Interestingly, in a few animal species, such vibrio intracellular stages have been associated with diseases. For example, the coral pathogens V. shiloi (Rosenberg and Falkovitz, 2004) and V. coralliilyticus (Vidal-Dupiol et al., 2011) enter coral epithelial cells as part of their pathogenic process. Similarly, the oyster pathogen $V$. tasmaniensis LGP32 enters oyster immune cells, the hemocytes, and this is required for virulence in oysters (Duperthuy et al., 2011).

Survival in professional phagocytes requires evading or resisting the phagosome hostile environment. Multiple stresses are used by professional phagocytes to kill phagocytosed microorganisms (Flannagan et al., 2009).

The NADPH oxidase produces potent reactive oxygen species (ROS) which are delivered into the phagolysosome during its maturation together with a series of hydrolytic enzymes and antimicrobial peptides. Moreover, an acidic environment is created by accumulating protons in the lumen of the phagosome. This environment is both aggressive to the phagocytosed bacteria and optimal for the activity of the hydrolytic enzymes. Such microbicidal mechanisms are broadly conserved throughout evolution (Boulais et al., 2010) and they have been well described in oyster hemocytes (Bachere et al., 2015).

While vibrio intracellular stages have been associated with the expression of key virulence factors (Ma et al., 2009; Zhang et al., 2012), it is still often unknown whether those stages play an essential role in pathological processes induced by vibrios. In the $V$. tasmaniensis LGP32/ oyster interaction, where vibrios behave as facultative intravacuolar pathogens (Vanhove et al., 2015), a tight correlation has been found between entry into host immune cells and virulence in experimental infections (Duperthuy et al., 2010; 2011). We indeed previously showed (i) that the major outer membrane protein OmpU of LGP32 was required for efficient plasma opsonization, $\beta$-integrin recognition and subsequent entry into oyster hemocytes (Duperthuy et al., 2011) and (ii) that ompUdeletion mutants were strongly attenuated in terms of virulence (Duperthuy et al., 2010). We also observed important cell damages in hemocytes heavily loaded with LGP32 (Vanhove et al., 2015), suggesting that phagocytosed LGP32 could be cytotoxic to oyster hemocytes. Supporting this hypothesis, some virulence factors were shown to be secreted by outer membrane vesicles released by LGP32 inside the phagosome (Vanhove et al., 2015). To the best of our knowledge, it is so far the only model in which invasion of professional phagocytes by vibrios has been so clearly associated 
with disease expression in vivo. Therefore, this model offers a great opportunity to decipher the causal relationships between intracellular stages and virulence in vibrios and decipher the molecular bases of vibrio survival in the hostile environment of the phagosome.

Here, we took advantage of this model to characterize vibrio intracellular stages and identify key functions required for vibrio intracellular survival in immune cells. LGP32 cytotoxicity was found to depend upon entry and survival in oyster hemocytes. By comparative transcriptomics, we identified antioxidant responses and copper efflux as functions highly induced intracellularly. Their key role in intracellular survival and cytotoxicity to host immune cells was demonstrated genetically. Altogether, our results identify copper homeostasis as a key player in the vibrio/phagocyte interaction and copper efflux as a major vibrio adaptive trait for oyster tissue colonization and virulence in oyster experimental infections.

\section{Results}

Phagocytosis and intracellular survival of LGP32 are required to induce cytolysis

Characterization of the $V$. tasmaniensis strain LGP32/ hemocyte interactions at the cellular level was performed by infecting primary cultures of oyster hemocytes maintained in sterile sea water (SSW) with GFP-expressing strains opsonized in oyster plasma. Plasma-opsonized LGP32 grew significantly in hemocyte co-cultures $(P<0.001)$, unlike the phylogenically related LMG $20012^{\top}$ (Thompson et al., 2003), an avirulent control strain used in our previous study (Duperthuy et al., 2011; Fig. 1A). However, plasma-opsonized LGP32 was unable to grow in SSW in the absence of hemocytes (Fig. 1A), which showed that hemocytes are required to support the growth of LGP32 in such a nutrient-poor environment. The hemocyte/vibrio interaction was then monitored over the first $5 \mathrm{~h}$ of contact by epifluorescence microscopy. After a $1 \mathrm{~h}$ contact, oyster hemocytes were already heavily loaded with either LGP32 or LMG $20012^{\top}$. After 3 h, most LGP32 were intravacuolar but some bacteria-containing hemocytes harbouring cellular alterations had lost adherence: they were found in the culture supernatant together with some extracellular vibrios. After $5 \mathrm{~h}$, no more LGP32containing hemocytes were adherent; several hemocytes were present in the supernatant and most of the LGP32 were extracellular (Figs 1B, Supporting Information Fig. S1). On the contrary, LMG $20012^{\top}$ remained within hemocytes over the course of the experiment without any sign of hemocyte alteration. Therefore, LGP32 entry into hemocytes triggers a loss of hemocyte integrity leading to the release of LGP32 through cytolysis $\sim 5 \mathrm{~h}$ after phagocytosis.

To quantify the LGP32-induced cytolysis of hemocytes, we used the cell impermeant Sytox green DNA dye. In agreement with our microcopy data (Fig. 1B), 5 to $7 \mathrm{~h}$ after LGP32 phagocytosis, hemocyte monolayers generated a massive Sytox green fluorescent signal as opposed to LMG $20012^{\top}$ ( $P<0.001$; Fig. 1C). Thus, alteration of hemocyte membrane integrity is observed after LGP32 phagocytosis. Remarkably, cytochalasin D, an inhibitor of F-actin polymerization that prevents phagocytosis, abolished LGP32-induced hemocyte cytolysis (Fig. 1C). We concluded that 
cytotoxicity of LGP32 towards oyster hemocytes is strictly dependent on phagocytosis. Altogether, those results show that intracellular LGP32 resists to the hemocyte killing machinery, and within few hours becomes cytotoxic, thereby promoting a hemocyte cytolysis that could sustain its own growth.

\section{Antioxidant responses and metal homeostasis genes are highly expressed intracellularly}

To identify the mechanisms involved in LGP32 resistance to the hemocyte killing machinery and phagocytosisdependent cytotoxicity, we used a global comparative RNAseq approach early after vibrio entry into hemocytes

(1 $\mathrm{h}$ after phagocytosis). Transcripts of intracellular LGP32 were obtained from hemocyte monolayers and their relative level of expression was compared with that of transcripts of extracellular LGP32 obtained from vibrios kept in SSW alone. Out of 3230 genomic elements (not including rRNA genes), transcript levels of 1280 genes varied by more than fourfold in the intracellular condition, with a false detection rate of $5 \%$ in all triplicate conditions (Supporting Information Table S1; GEO Submission GSE73260). The RNAseq results were validated by qRTPCR for $84 \%$ of the tested genes on another set of three independent experiments (Supporting Information Fig. S2). RNAseq revealed a massive activation of LGP32 metabolism inside the hemocytes. Indeed, the three functional categories that gathered most of the differentially expressed genes were protein synthesis, carbon compound utilization and transport, and amino acid transport and metabolism. An important up-regulation of genes involved in glycogenesis, gluconeogenesis, TCA cycle, as well as in envelope, LPS and capsule biogenesis was also observed (Supporting Information Table S1; Table 1).

Finally, stress response and metal homeostasis were functions highly impacted by the intracellular environment.

Copper efflux and antioxidant genes were the most highly induced in the intracellular environment. Indeed, among 34 genes overexpressed more than 50 times (i.e. $0.8 \%$ of the transcriptome; Table 2), five genes were involved in copper efflux: cusCBAF (VS_II0514, VS_II0515, VS_II0516, VS_II0517) and copA (VS_0768), which encode a RND-transporter and a P-type ATPase respectively. Three additional genes were involved in the antioxidant response, namely sodA (VS_2918) and ahpC/ahpF (VS_2126, VS_2127), which encode a superoxide dismutase and an alkyl hydroperoxide reductase complex respectively. As RNAseq was performed in whole hemolymph, we evaluated the respective role of plasma versus the intracellular environment on the expression of candidate genes. As a control, vibrios were incubated in SSW for the same times. While the antioxidant genes $a h p C$ and sodA were induced only after entry into hemocytes $(P<0.01)$, copper efflux genes copA and cusB were already induced in oyster plasma $(P<0.01)$. Still, after $1 \mathrm{~h}, \operatorname{cop} A$ expression remained 20 times higher in the intracellular condition than in the extracellular controls $(P<0.01$; Fig. 2). 
The antioxidant sodA gene is required for intracellular 
To determine whether the antioxidant response was necessary for LGP32 intracellular survival and phagocytosisdependent cytotoxicity, we constructed deletion mutants lacking sodA (VS_2918) and ahpC (VS_2126). As a second copy of ahpC (VS_2126) referred to as tsa (VS_0593) was found in LGP32 genome (39.8\% amino acid identity), we also constructed a $\Delta a h p C /$ tsa double mutant. Deletions were confirmed by PCR and sequencing (Supporting Information Fig. S3). Growth in Zobell medium or plasma and phagocytosis efficiency did not significantly differ from the wild-type LGP32 (Supporting Information Figs S4 and S5). Interestingly, for $\Delta$ sodA, but not $\Delta a h p C$ nor $\Delta a h p C /$ tsa (Supporting Information Fig. S6), we observed a strongly attenuated phagocytosis-dependent growth $(P<0.001)$ and cytotoxicity $(P<0.001)$ compared with the wild-type LGP32 (Fig. 3A and B). Complementation of $\triangle \operatorname{sod} A$ with $\mathrm{pMRB}$ plasmids encoding $\operatorname{sod} A$ led to a dose-dependent restoration of the LGP32 cytotoxicity to hemocytes (Fig. 3B). Altogether, those results show the essential role of sodA in LGP32 resistance to phagocyte killing and subsequent cytotoxicity to hemocytes. However, the $\Delta$ sodA deletion mutant did not show any significant virulence attenuation in oyster experimental infections (Fig. 3C).

copA is required for copper resistance, intracellular survival and cytotoxicity in phagocytes

Isogenic mutants lacking copA (VS_0768) or cusAB (VS_II0515, VS_II0516) were constructed (Supporting Information Fig. S3) to study the role of copper efflux in the intracellular survival and virulence of LGP32. Growth in Zobell medium or plasma and phagocytosis efficiency did not significantly differ from the wild-type LGP32 (Supporting Information Figs S4 and S5). Both deletion mutants were then tested for resistance to copper and zinc (as a control of metal specificity) by zone inhibition assay. $\triangle$ copA showed a major increase in susceptibility to copper compared with the wild-type LPGP32, but remained equally susceptible to zinc (Supporting Information Fig. S7). Complementation with a pMRB plasmid carrying copA restored resistance to high copper concentrations. No significant difference was observed for the $\triangle$ cusAB mutant in our in vitro assays (Supporting Information Figs S7 and S8). In hemocyte co-cultures, the phagocytosis-dependent growth of LGP32 was strongly attenuated in the $\triangle$ copA mutant $(P<0.001$; Fig. 4A). Moreover, the $\triangle$ copA mutant was two times less cytotoxic than the wild-type LGP32 ( $P<0.001$; Fig. 4B). Importantly, complementation restored the cytotoxicity in hemocytes to wild-type levels (Fig. 4B). This confirmed the essential role of copA in LGP32 resistance to copper, intracellular survival and subsequent cytolysis of host cells.

copA is required for host colonization and virulence in experimental infections

In vivo studies were performed to characterize the role of copA in LGP32 pathogenesis. In experimental infections of juvenile oysters, the $\triangle c o p A$ mutant showed a significantly attenuated 
virulence. Indeed, mortalities at day 7 dropped from 85\% for wild-type LGP32 down to 65\% ( $P<$ 0.01) for the $\triangle$ copA mutant (Fig. $4 C$ ). To investigate the behaviour of the $\triangle$ copA mutant in vivo, colonization was tested by injecting juvenile oysters with GFP-labelled LGP32 or $\triangle \operatorname{cop} A$. The $\triangle \operatorname{copA}$ mutant showed a significant colonization defect with only $5757 \pm 4096 \mathrm{cfu} \mathrm{g}^{-1}$ of oyster flesh as opposed to $26700 \pm 4096 \mathrm{cfu} \mathrm{g}^{-1}$ for LGP32 ( $\left.P<0.05\right)$, as soon as $2 \mathrm{~h}$ after injection (Fig. 4D). Importantly, confirming our in vitro data (Fig. 1B), LGP32 induced a major cytolysis of oyster hemocytes and the release of extracellular bacteria in vivo (Fig. 4F), whereas $\triangle$ copA remained intracellular with most hemocytes showing preserved cell integrity (Fig. 4F). In agreement with the observed $\triangle$ copA colonization defect, $\triangle$ copA was massively and significantly $(P<0.01)$ outcompeted by the wild-type LGP32 in co-infection assays where oysters were injected with identical doses of GFP-expressing LGP32 and mCherry-expressing LGP32 or $\triangle$ copA. We indeed measured very low competitive indexes $(\mathrm{Cl})=0.12 \pm 0.05$ and $0.03 \pm 0.05,2 \mathrm{~h}$ and $24 \mathrm{~h}$ after injection respectively (Fig. $4 \mathrm{E})$. Co-injection of GFP- and mCherry-expressing wild-type LGP32 gave $\mathrm{Cl} \sim 1(0.81 \pm 0.31$ and 1.04 \pm 0.31 at $2 \mathrm{~h}$ and $24 \mathrm{~h}$, respectively), confirming the absence of bias due to the fluorescent protein expression plasmids used here (Fig. 4E). Altogether, these data show that copper efflux is essential for LGP32 survival in hemocytes, expression of intracellular cytotoxicity, host colonization and virulence in experimental infections.

\section{Discussion}

As an increasing number of pathogenic vibrio species have been shown to adopt intracellular stages (Rosenberg and Falkovitz, 2004; Duperthuy et al., 2011; Zhang et al., 2012; de Souza Santos and Orth, 2014) understanding the mechanisms by which vibrios survive intracellularly has become a priority. Here, we developed a transcriptomic analysis coupled to in vitro and in vivo functional genomics, through which we identified functions essential for vibrio intracellular survival. Overall, our study provides important insights in several aspects. First, it is to our knowledge the first global characterization of the molecular functions sustaining intracellular life in a vibrio strain whose virulence depends on its intracellular survival in phagocytes. Second, we functionally characterized the antioxidant response and metal homeostasis as two major functions widely conserved among vibrios and essential for vibrio intracellular stages. Third, we identified copper tolerance as a major determinant of vibrio fitness at the host-pathogen interface.

Vibrio tasmaniensis LGP32 was chosen in this study as it has evolved the capacity to survive in oyster hemocytes (Duperthuy et al., 2011). Our present study showed that a phagocytosis step was required for LGP32 to finally induce cytolysis of oyster immune cells. Such an intracellular LGP32driven cytolysis of hemocytes was dependent on LGP32 entry and survival inside hemocytes, as demonstrated with phagocytosis-inhibiting drugs or mutants impaired in intracellular survival. Since 
circulating phagocytes were highly damaged in infected oysters, the LGP32-driven cytolysis of oyster hemocytes could cause a dramatic immune suppression of oyster defences promoting pathogenesis.

Oyster hemocytes are immune cells equipped with a complete panel of microbicidal functions (Bachere et al., 2015). In particular, they respond to phagocytosis by a rapid and massive oxidative burst highly toxic to phagocytosed microorganisms (Poirier et al., 2014). Consistently, the antioxidant response was essential to LGP32 survival in the phagosome hostile environment. sodA (VS_2918) and ahpC/ahpF (VS_2126, VS_2127) were among the genes most highly induced intracellularly. Moreover, MnSOD (sodA gene product) was essential for LGP32 intracellular survival and cytotoxicity in oyster phagocytes. By catalysing the conversion of the highly toxic superoxide ion $\left(\mathrm{O}_{2}^{-}\right)$to $\mathrm{H}_{2} \mathrm{O}_{2}$ and dioxygen $\left(\mathrm{O}_{2}\right)$ SODs contribute to tolerance to oxidative stress (Kang et al., 2007) and resistance to acidic pH (Kim et al., 2005) in diverse vibrio species. In V. vulnificus, signals inducing MnSOD expression include low iron and acidic pH (Kim et al., 2005), which are signals likely encountered by LGP32 in the phagosome as an active influx of iron and efflux of cations is observed (Supporting Information Table S1).

We report here the essential role of a MnSOD in the intracellular survival of a vibrio species, whereas in the coral pathogen V. shiloi, a FeSOD contributes to survival in coral ectodermal cells (Banin et al., 2003). Interestingly, in Escherichia coli, MnSOD is expressed under ironlimiting conditions, when FeSOD is repressed (Niederhoffer et al., 1990). This may explain why MnSOD plays a crucial role in LGP32 intraphagosomal stages, where iron is scarce as indicated by the intracellular activation of iron uptake (Supporting Information Table S1). From our present data and studies on V. shiloi (Banin et al., 2003), Fe and MnSODs, which share a common ancestor, are required for intracellular survival of at least two pathogenic vibrio species. As they are highly conserved across vibrios, they could be involved in the intracellular survival of additional vibrio species.

One major result of our work is the identification of the essential role of metal homeostasis and copper efflux in particular in vibrio intracellular life and subsequent cytotoxicity, colonization and virulence in oyster experimental infections. However, in the last decade metal homeostasis has been highlighted to play a role in different bacterial pathogenesis in vertebrates (Becker and Skaar, 2014). Among the different metals involved at the host- pathogen interface, the toxicity of copper appears to be mainly used as a defence mechanism by hosts. Hence, copper efflux is an important mechanism for pathogens to avoid copper toxicity. Indeed, free copper enhances the production of reactive oxygen species (ROS) that create damages to a broad series of macromolecules and largely contribute to copper antimicrobial properties (Hodgkinson and Petris, 2012). In $\mathrm{H}_{2} \mathrm{O}_{2}$-rich environments like the phagosome, the redox properties of $\mathrm{Cu}(\mathrm{I})$ catalyse the generation of highly toxic hydroxyl radicals $\left(\mathrm{OH}^{-}\right)$. Consistent with its major protective role against hemocyte intracellular killing, CopA (VS_0768) of LGP32, a member of the P-type ATPase family exporting Cu(I) 
across the plasma membrane (Hodgkinson and Petris, 2012), was highly transcribed in the phagosome. P-type ATPases homologous to CopA have been described in diverse species of intracellular bacteria like Salmonella (CopA; Espariz et al., 2007) and Mycobacterium (CtpV) that invade mammalian phagocytes (Rowland and Niederweis, 2012). As in oyster hemocytes, genes encoding copper-exporting P-type ATPase are upregulated by such pathogens when they enter phagosomes of macrophages (Chaturvedi and Henderson, 2014) in which copper concentration increases up to several hundred micromolar (Wagner et al., 2005).

The major role of CopA in LGP32 intracellular survival strongly suggests that phagosomes of oyster hemocytes accumulate copper to control phagocytosed pathogens and supports recent findings showing that both hosts and pathogens manipulate copper content in infected host niches (Chaturvedi and Henderson, 2014; Chaturvedi et al., 2014). In particular, mammalian phagocytes have been shown to modulate the intraphagosomal concentration of metals, by depriving microorganisms from essential metals like iron or accumulating toxic metals like copper (Hood and Skaar, 2012). Thus, in human macrophages, metal homeostasis is essential for the control of phagocytosed bacteria (Soldati and Neyrolles, 2012). The main effectors of copper influx in phagosomes of macrophages are CTR1 and ATP7A (Hodgkinson and Petris, 2012) whose expression is essential for the copper-mediated bactericidal activity of the phagosome (White et al., 2009). Interestingly, three ATP7A and two CTR1 genes are found in the genome of Crassostrea gigas (Genbank accession numbers gbIEKC33905.1, gbIEKC18325.1, gbIEKC28422.1 and gbIEKC31900.1, gbIEKC33878.1). Thus, like mycobacteria replicating inside phagosomes (Neyrolles et al., 2015), LGP32 uses copper efflux to resist the high copper concentrations to which it is exposed after phagocytosis. It has been hypothesized that copper detoxification has been conserved during evolution to provide protection against phagocytosis (Raimunda et al., 2011; German et al., 2013). This hypothesis is supported by the present data, which show that pathogens capable to survive inside phagocytes of invertebrates (here the oyster) use strategies similar to pathogens surviving inside macrophages of vertebrates. This high degree of conservation is consistent with the high conservation of the phagocytotic machinery that intracellular pathogens have to face, from protozoan to metazoan phagocytic cells (Boulais et al., 2010). The major role of copper homeostasis at the host- pathogen interface may well go beyond its role in intracellular survival. Indeed, copper efflux was induced as soon as LGP32 entered oyster plasma and was essential for oyster colonization. This is consistent with the copperrich composition of marine invertebrate plasma, which is characterized by abundant copper-containing proteins like $\mathrm{Zn} / \mathrm{Cu}$ SODs in the oyster (Gonzalez et al., 2005; Duperthuy et al., 2011) or hemocyanin in crustaceans and cephalopods (Terwilliger and Dumler, 2001) to which squid-colonizing vibrios resist (Kremer et al., 2014). A recent study suggested that copA is required for the colonization of the squid light organ by $V$. fischeri 
(Brooks et al., 2014). We show here for the first time the central role of copA in the pathogenic potential of a vibrio.

The gene copA is highly conserved among vibrios and to a broader extent among bacteria (Hernandez-Montes et al., 2012). Hence, copA has been used to evaluate the impact of copper-rich environments on bacterial communities, suggesting that copA is under selection in copperrich environments (Besaury et al., 2013). In the wild, copper accumulation often originates from humanrelated activities and numerous aquatic animals can accumulate copper in their tissues, including oysters (Luo et al., 2014). Therefore, copper abundance in different environmental niches, including invertebrates as well as copper of natural or anthropogenic sources, may represent an important driver for the emergence of copper resistant pathogens. In conclusion, this study demonstrates the essential role of copper efflux and antioxidants in vibrio survival inside host cells and suggests that interactions of vibrios with different copper-rich environmental niches could select important adaptive traits favouring emergence of water-borne pathogens.

\section{Experimental procedures}

\section{Animals}

Adult diploid C. gigas were purchased from the local oyster farm in Le Petit Mas (Mèze, France) and used for RNAseq and qRT-PCR analyses. Adult triploid $C$. gigas were purchased from the local oyster farm at the 'CAT de Maguelone' (Palavas, France) to perform in vitro cell biology experiments. For

experimental infections, juvenile diploid $C$. gigas oysters were provided by the Ifremer oyster hatcheries of Argenton and Bouin (France).

\section{Bacterial strains and culture conditions}

Vibrio isolates were grown in Zobell or on Zobell agar (Saulnier et al., 2000), Luria-Bertani (LB) or LBagar (LBA) $+\mathrm{NaCl} 0.5 \mathrm{M}$, at $20^{\circ} \mathrm{C}$. E. coli strains were grown in LB or on LBA at $37^{\circ} \mathrm{C}$. Chloramphenicol $\left(5-25 \mu \mathrm{g} \mathrm{ml}^{-1}\right)$, thymidine $(0.3 \mathrm{mM})$ and diaminopimelate $(0.3 \mathrm{mM})$ were added as supplements when necessary. Induction of the $\mathrm{P}_{\mathrm{BAD}}$ promoter was achieved by the addition of $0.2 \% \mathrm{~L}$-arabinose to the growth medium, and conversely, repression was obtained by the addition of $1 \%$ D-glucose.

\section{Plasmid construction and mutagenesis}

Mutagenesis was performed by gene replacement, as described in (Lemire et al., 2014). Two independent PCR amplifications of the regions (500 bp) flanking the gene to delete were performed using two primer pairs ( $1+2$ and $3+4$; Supporting Information Table S2). An inside out PCR was performed using the pSW7848T suicide vector DNA (Val et al., 2012) and primer pair pSW-F and pSW-R (Supporting Information Table S2). The recombinant plasmid was then assembled by the Gibson assembly method using the Gibson assembly master mix (New England Biolabs, NEB) 
according to the manufacturer's instructions. Mutants were screened by PCR using external primer $5+6$ listed in Supporting Information Table S2. For complementation experiment, the gene of interest was cloned under the control of a constitutive PLAC promoter in a PMRB plasmid (Le Roux et al., 2011). Two independent $P C R$ amplifications of the gene and plasmid were performed using the primers gene- $F+R$ and $p M R B-F+R$ reciprocally. After purification and quantification, $100 \mathrm{ng}$ of the PCR products were mixed with the Gibson assembly Master Mix and incubated for $60 \mathrm{~min}$ at $50^{\circ} \mathrm{C}$. Samples were diluted $1 / 3$ before $E$. coli transformation. Clones were controlled by digestion with restriction enzyme and sequencing of PCR products obtained using the primers described in Supporting Information Table S2. Strains $\pi 3813$ and $\beta 3914$ were used as plasmid hosts for cloning and conjugation respectively (Le Roux et al., 2007). Conjugation was carried out as described in Goudenège et al., 2014. Plasmids and strains used and/or constructed in the present study are presented in Supporting Information Table S2.

\section{Preparation of vibrios and oyster hemocytes for in vitro assays}

Hemolymph was collected from the adductor muscle of oysters using a $2 \mathrm{ml}$ syringe with a 23-G needle. After cell counting, freshly collected hemolymph was dispensed in wells to obtain hemocytes monolayers in the desired plate format (see below). In parallel, after growing vibrio strains at $20^{\circ} \mathrm{C}$ in Zobell medium for $14 \mathrm{~h}$, bacteria were washed in sterile sea water (SSW) by two successive centrifugations $\left(10 \mathrm{~min}, 1000 \mathrm{~g}, 20^{\circ} \mathrm{C}\right.$ ) and diluted in SSW at a working dilution of $2.10^{\circ} \mathrm{cfu}$ $\mathrm{ml}^{-1}$ as deduced from $\mathrm{OD}_{600}$ reads. When needed, bacteria were opsonized for one hour in $0.22 \mu \mathrm{m}$ filtered oyster plasma.

In vitro assay for vibrio intracellular survival

Hemocytes $\left(2 \times 10^{5}\right.$ hemocytes per well) were plated in Black 96-wells plate with transparent flat bottom and kept in plasma. Vibrio strains carrying high copy pMRB-GFP plasmid (Supporting Information Table S2) were opsonised in oyster plasma. Opsonized vibrio strains were then added to the hemocyte monolayers at a multiplicity of infection of 50:1. Binding of bacteria to hemocytes was synchronized by a brief centrifugation of $5 \mathrm{~min}$ at $400 \mathrm{~g}$. After $1 \mathrm{~h}$ of phagocytosis, hemocytes were carefully washed three times with SSW to remove any remaining extracellular bacteria. Then, GFP fluorescence was measured every hour over $20 \mathrm{~h}$ using a TECAN plate reader ( $\lambda$ ex $480 \mathrm{~nm} / \lambda \mathrm{em}$ $520 \mathrm{~nm}$ ). In each experiment, each condition was performed in triplicates and the depicted results are the average of three independent experiments. Statistical analysis was performed using RMANOVA over the independent experiments.

In vitro cytotoxicity assay

Hemocytes $\left(2 \times 10^{5}\right.$ hemocytes per well) were plated in Black 96-wells plate with transparent flat bottom. After $1 \mathrm{~h}$ of adhesion and plasma removal, $10 \mu \mathrm{g} \mathrm{ml}^{-1}$ of Sytox Green (Molecular Probes) 
diluted in $200 \mu \mathrm{l} \mathrm{SSW}$ was added to each well. Opsonized vibrio strains were then added to the hemocyte monolayers at a multiplicity of infection of 50:1. Binding of bacteria to hemocytes was synchronized by a brief centrifugation of $5 \mathrm{~min}$ at $400 \mathrm{~g}$. Sytox Green fluorescence was determined ( $\lambda$ ex $480 \mathrm{~nm} / \lambda$ em $550 \mathrm{~nm}$ ) every 30 min over $14 \mathrm{~h}$ using a TECAN microplate reader. For controls, washed bacteria were incubated in Sytox Green diluted in SSW. Maximum cytolysis was determined by incubating hemocytes in Sytox Green in presence of $0.1 \%$ Triton X-100. To determine the role of phagocytosis in vibrio-induced cytolysis of hemocytes, hemocytes were incubated with $5 \mu \mathrm{ml}^{-1}$ of

cytochalasin D, an actin polymerization inhibitor, $30 \mathrm{~min}$ before adding vibrios. The results are representative of three independent experiments. The RM-ANOVA test was used to estimate the $P$ values of the comparison.

\section{Fluorescence microscopy}

Hemocytes were plated onto glass coverslips in a 24-well plate to obtain monolayers of $5 \times 10^{5}$ cells. After adhesion, hemocytes were exposed to GFP-expressing vibrios (washed in SSW) at a multiplicity of infection of 50:1. Binding of bacteria to hemocytes was synchronized by a brief centrifugation of $5 \mathrm{~min}$ at $400 \mathrm{~g}$. After $1 \mathrm{~h}, 3 \mathrm{~h}$ and $5 \mathrm{~h}$-incubation time, culture supernatants were fixed with $4 \%$ paraformaldehyde for $15 \mathrm{~min}$ and cytospun on glass slides for $5 \mathrm{~min}$ at $1000 \mathrm{~g}$. The cell monolayers (coverslips from bottom of the wells), were also fixed with $4 \%$ paraformaldehyde for $15 \mathrm{~min}$. Glass slides and coverslips were then washed in PBS and stained with $0.25 \mu \mathrm{g} \mathrm{m}^{-1}$ DAPI (Sigma) and 0.5 $\mu \mathrm{g} \mathrm{ml} \mathrm{m}^{-1}$ Phalloidin-TRITC (Sigma). Fluorescence imaging was performed using a Zeiss Axioimager fluorescence microscope and a Zeiss 63× Plan-Apo 1.4 oil objective equipped with a Zeiss MRC black and white camera for image acquisition.

\section{Vibrio transcriptomic analysis by RNAseq}

LGP32 was grown at $20^{\circ} \mathrm{C}$ in Zobell medium for $10 \mathrm{~h}$ and washed twice in SSW by centrifugations $\left(10 \mathrm{~min}, 1000 \mathrm{~g}, 20^{\circ} \mathrm{C}\right)$. Bacteria were then resuspended in SSW at $\mathrm{OD}_{600}$ of $0.5\left(1.10^{9} \mathrm{cfu} \mathrm{ml}^{-1}\right.$ equivalent). Hemolymph was collected from the adductor muscle of oysters using a $2 \mathrm{ml}$ syringe with a 23-G needle. Freshly collected hemolymph was dispensed in a 6-well plate to obtain monolayers of $6 \times 10^{6}$ hemocytes per well. One hour after plating, vibrios were added at a multiplicity of infection of 100:1, and plates were centrifuged for $5 \mathrm{~min}$ at $400 \mathrm{~g}$ for binding synchronization. After $1 \mathrm{~h}$ of co-incubation, wells were washed extensively three times with SSW to remove extracellular bacteria and $500 \mu$ l Trizol reagent (Invitrogen) was added to every well for total RNA extraction. The efficiency of vibrios internalization in hemocytes was verified by microscopy showing that about $40 \%$ of hemocytes internalized about 50-70 bacteria, with rare bacteria remaining extracellular. As a control, washed bacteria were incubated in triplicates in SSW for $1 \mathrm{~h}$ and resuspended in Trizol after centrifugation. RNA from three independent experiments of LGP32 phagocytosis by hemocytes was extracted using the Trizol reagent protocol (Life Technologies). RNA concentration was measured using a NanoDrop 1000 Spectrophotometer (Thermo Fisher Scientific 
Inc.) and RNA quality was monitored by agarose gel electrophoresis and a 2100 Bioanalyzer (Agilent Technologies Inc.). The bioanalyser analysis showed that bacterial RNAs represented approximately $10 \%$ of the total RNA in the intrahemocyte samples. Accordingly, control samples were prepared by mixing total RNA extracted from LGP32 incubated in SSW with $C$. gigas hemocyte RNA with a ratio of 1:9. For each sample, $7 \mu \mathrm{g}$ of starting material was treated with DNasel (4 U) (Ambion's DNAfree $^{\mathrm{TM}}$ ) following the manufacturer's instructions. Samples were then enriched in bacterial RNA using the MICROBEnrich ${ }^{\mathrm{TM}} \mathrm{Kit}$ (Ambion) and bacterial rRNA were then removed by the MICROBExpress ${ }^{\mathrm{TM}} \mathrm{Kit}$ (Ambion) following the manufacturer's instructions. Because the MICROBEnrich ${ }^{\mathrm{TM}}$ Kit is based on oligonucleotides that are designed to capture rRNAs from mammal species, it is not fully efficient to remove invertebrate rRNAs. Accordingly, we performed a further depletion step using a 5'-phosphatedependent exonuclease (Terminator, Epicentre), that degrades processed transcripts, following instructions from the manufacturer. For cDNA sequencing, for each sample, a directional cDNA library was constructed and sequenced on an illumina Hiseq 1000, in paired-end reads of $2 \times 100 \mathrm{bp}$. Three samples were multiplexed per lane giving $\sim 60 \times 10^{6}$ reads per sample. Out of 50-60 M reads obtained from the RNA-seq, 1.2 M reads from the SSW samples and 2.3 $\mathrm{M}$ reads from the intrahemocyte samples were successfully mapped onto the genome of LGP32.

\section{Sequencing data analysis}

Transcriptomic high throughput sequencing data were analysed using a bioinformatic pipeline implemented in the Microscope platform (Vallenet et al., 2013). The current pipeline is a 'Master' shell script that launches the various parts of the analysis (i.e. a collection of Shell/Perl/R scripts) and controls for all tasks having been completed without errors. In a first step, the RNA-Seq data quality was assessed by including option like reads trimming or merging/split pairedend reads. In a second step, reads were mapped onto the $V$. tasmaniensis LGP32 genome (genome ID: 13995, assembly GCA_000091465.1, NCBI) using the SSAHA2 package (Ning et al., 2001) that combines the SSAHA searching algorithm (sequence information is encoded in a perfect hash function) aiming at identifying regions of high similarity, and the cross-match sequence alignment programme (Ewing et al., 1998), which aligns these regions using a banded Smith-Waterman-Gotoh algorithm (Smith and Waterman, 1981). An alignment score equal to at least half of the read is required for a hit to be retained. To lower false positives discovery rate, the SAMtools (v.0.1.8; Li et al., 2009) are then used to extract reliable alignments from SAM formatted files. The number of reads matching each genomic object harboured by the reference genome is subsequently computed with the Bioconductor-Genomic-Features package (Carlson et al., 2011). In case of reads matching several genomic objects, the count number is weighted in order to keep the same total number of reads. Finally, the Bioconductor-DESeq package (Anders and Huber, 2010) with default parameters is used to analyse raw counts data and test for differential expression between conditions. Out of the paired-end reads, only mapping results of the first sequencing run reads were used for the DESeq analysis. 
qRT-PCR analyses

Experiments were performed as for 'Vibrio transcriptomic analysis by RNAseq'. Conditions tested were: $6 \times 10^{8}$ vibrios per well in SSW (control), vibrios in oyster plasma and vibrios opsonized in plasma and incubated on hemocyte monolayers $\left(6 \times 10^{6}\right.$ hemocytes per well) kept in SSW. Vibrios were incubated $30 \mathrm{~min}, 1 \mathrm{~h}$ and $2 \mathrm{~h}$ before wells were centrifuged and the incubated stopped by adding $500 \mu \mathrm{l}$ Trizol per well. Total RNA was extracted from Trizol using the DirectZol RNA Miniprep kit (R2051) according to manufacturer's instructions (ZymoResearch) and then treated by DNasel to remove contaminating genomic DNA, using the DNA-free kit (Ambion) before purification by phenol/chloroform extraction and ethanol precipitation. Quantification of total RNA was done with a NanoDrop spectrophotometer (Thermo, Fisher Scientific) and quality was monitored using a 2100 Bioanalyzer (Agilent Technologies Inc.). Real-time qPCR was performed either at the Imagif platform (Gif sur Yvette) on an ABI 7900HT Fast Real-Time PCR System using a Fast SG qPCR Master Mix (Roboklon), or at the MGX platform in Montpellier using a the Light-Cycler 480 System (Roche), using the primers listed in Supporting Information Table S3. Relative expression was calculated using the 2- $\Delta \Delta$ Cq method (Pfaffl, 2001), with three genes, encoding 6PKF (VS_2913), MGS (VS_II1055) and CcmC (VS_0852) being used for normalization. These were chosen because their expression was found to be constant across conditions in the RNAseq, as well as by qRT-PCR.

\section{Copper and zinc sensitivity}

Paper discs $\left(6 \mathrm{~mm}\right.$ ) were loaded with $\mathrm{CuSO}_{4}$ by soaking them over-night into a $50 \mathrm{mM} \mathrm{CuSO}_{4}$ solution or 50 mM ZnSO4 solution. Cells from a stationary phase LGP32 wildtype and LGP32 isogenic mutant cultures at DO = 1 were washed twice with SSW before being spread onto agar plates containing 15

$\mathrm{g} \mathrm{L}^{-1}$ bactopeptone and $0.5 \mathrm{M} \mathrm{NaCl}$. Using a sterile tweezer, copper and zinc impregnated disks were placed on the bacterial lawn before incubation at $20^{\circ} \mathrm{C}$. After 5 day incubation, the diameter of the inhibition zone around the disk was measured.

\section{Experimental infections of oysters}

Experimental infections were performed at $20^{\circ} \mathrm{C}$, as previously described (Duperthuy et al., 2010). Groups of 45 oysters were injected with the different strains of LGP32 (4 × $10^{7}$ cfu per spat). An equal volume of SSW was injected to control animals. Colony-forming units of bacteria were determined by counting on Zobell agar plates. For each condition, oysters were placed for $24 \mathrm{~h}$ in three separate tanks in 6 I of seawater (15 animals per aquarium). Mortalities were followed during 7 days. The non-parametric Kaplan-Meier test was used to estimate log-rank values for comparing conditions. All experimental infections were performed according to the Ifremer animal care guidelines and policy.

In vivo colonization and damages to host cells 
After overnight growth in $\mathrm{LB} \mathrm{NaCl} 0.5 \mathrm{M}$ containing $10 \mu \mathrm{g} \mathrm{ml} \mathrm{m}^{-1}$ chloramphenicol, vibrio strains carrying high copy PMRBGFP were washed twice with sterile sea water (SSW) by centrifugation for $15 \mathrm{~min}$ at $1500 \mathrm{~g}$. Then, groups of 20 oysters were injected with wild-type or $\triangle$ copA LGP32 $\left(7 \times 10^{7}\right.$ cfu per oysters). Two hours after injection, hemocytes were collected from the adductor muscle of five oysters and fixed with $2 \%$ paraformaldehyde for $15 \mathrm{~min}$ and finally cytospun for $5 \mathrm{~min}$ at 1000 g. Samples were stained with $0.25 \mu \mathrm{g} \mathrm{m}^{-1}$ DAPI (Sigma) and $0.5 \mu \mathrm{g} \mathrm{m}^{-1}$ WGA-TRITC (Sigma). Fluorescence imaging was performed as described above. Statistical analysis was performed using non-parametric Mann- Whitney test for comparing both conditions. Similarly, $2 \mathrm{~h}$ after injection, five additional oysters injected with each strain were weighed and homogenized by passage through a Dounce apparatus. Serial dilutions of the homogenized material in SSW were spread onto LB NaCl $0.5 \mathrm{M}$ agar plates containing $10 \mu \mathrm{g} \mathrm{ml}^{-1}$ chloramphenicol, in duplicate. Colonies were counted after 2 days of growth at $20^{\circ} \mathrm{C}$ and results were expressed in number of colony forming units per gram of oyster.

In vivo competitive index

After overnight growth in $\mathrm{LB} \mathrm{NaCl} 0.5 \mathrm{M}$ containing $10 \mu \mathrm{g} \mathrm{m} \mathrm{m}^{-1}$ chloramphenicol, wild-type or $\Delta \operatorname{cop} A$ LGP32 carrying high copy pMRB-GFP and wild-type LGP32 high copy pMRBmCherry were washed twice in SSW by centrifugation for $15 \mathrm{~min}$ at $1500 \mathrm{~g}$. Then, groups of 40 oysters were injected with a 1:1 ratio of each strain $\left(7 \times 10^{7} \mathrm{cfu}\right.$ per oysters). Two conditions were tested: GFP-wildtype/mCherry-wild-type (control) as well as GFP- $\triangle$ copA/mCherry-wild-type. Five oysters of each condition were homogenized and plated on agar plates as for the colonization assay. Red colonies (wildtype) and green colonies (mutant) were counted and results were expressed as the ratio of mutant CFUs over wild-type CFUs. Statistical analysis was performed using the nonparametric Kruskal-Wallis test with Dunn's multiple comparisons test for comparing conditions.

\section{Acknowledgements}

This study received financial support from the ANR (Vibriogen project, ANR-11-BSV7-0023). We thank Dr Stéphane Cruveiller and Dr Claudine Médigue for RNAseq supervision as well as Dr Julien de Lorgeril and Phillipe Clair for precious advice for qRT-PCR analyses. We thank Bruno Petton and Max Nourry from the Ifremer for providing standardized oyster spat for experimental infections. We thank Marc Leroy for technical assistance. We are indebted to the Montpellier RIO Imaging platform of the University of Montpellier. This work has benefited from the facilities and expertise of the high through put sequencing and the qPCR platforms of IMAGIF (Centre de Recherche de Gifwww.imagif.cnrs.fr). 


\section{References}

Anders, S., and Huber, W. (2010) Differential expression analysis for sequence count data. Genome Biol 11: R106. Bachere, E., Rosa, R.D., Schmitt, P., Poirier, A.C., Merou, N., Charriere, G.M., and Destoumieux-Garzon, D. (2015) The new insights into the oyster antimicrobial defense: cellular, molecular and genetic view. Fish Shellfish Immunol 46: 50-64.

Banin, E., Vassilakos, D., Orr, E., Martinez, R.J., and Rosenberg, E. (2003) Superoxide dismutase is a virulence factor produced by the coral bleaching pathogen Vibrio shiloi. Curr Microbiol 46: 418422.

Becker, K.W., and Skaar, E.P. (2014) Metal limitation and toxicity at the interface between host and pathogen. FEMS Microbiol Rev 38: 1235-1249.

Besaury, L., Bodilis, J., Delgas, F., Andrade, S., De la Iglesia, R., Ouddane, B., and Quillet, L. (2013) Abundance and diversity of copper resistance genes cusA and copA in microbial communities in relation to the impact of copper on Chilean marine sediments. Mar Pollut Bull 67: 16-25.

Boulais, J., Trost, M., Landry, C.R., Dieckmann, R., Levy, E.D., Soldati, T., et al. (2010) Molecular characterization of the evolution of phagosomes. Mol Syst Biol 6: 423.

Brooks, J.F., 2nd, Gyllborg, M.C., Cronin, D.C., Quillin, S.J., Mallama, C.A., Foxall, R., et al. (2014) Global discovery of colonization determinants in the squid symbiont Vibrio fischeri. Proc Natl Acad Sci USA 111: 17284-17289.

Carlson, M., Pages, H., Aboyoun, P., Falcon, S., Morgan, M., Sarkar, D., and Lawrence, M. (2011). In GenomicFeatures: Tools for Making and Manipulating Transcript Centric Annotations. Maintainer, B.P. (ed.). pp. 1-66.

Chaturvedi, K.S., and Henderson, J.P. (2014) Pathogenic adaptations to host-derived antibacterial copper. Front Cell Infect Microbiol 4: 3.

Chaturvedi, K.S., Hung, C.S., Giblin, D.E., Urushidani, S., Austin, A.M., Dinauer, M.C., and Henderson, J.P. (2014) Cupric yersiniabactin is a virulence-associated superoxide dismutase mimic. ACS Chem Biol 9: 551-561.

Duperthuy, M., Binesse, J., Le Roux, F., Romestand, B., Caro, A., Got, P., et al. (2010) The major outer membrane protein OmpU of Vibrio splendidus contributes to host antimicrobial peptide resistance and is required for virulence in the oyster Crassostrea gigas. Environ Microbiol 12: 951- 963.

Duperthuy, M., Schmitt, P., Garzon, E., Caro, A., Rosa, R.D., Le Roux, F., et al. (2011) Use of OmpU porins for attachment and invasion of Crassostrea gigas immune cells by the oyster pathogen Vibrio splendidus. Proc Natl Acad Sci USA 108: 2993-2998.

Espariz, M., Checa, S.K., Audero, M.E., Pontel, L.B., and Soncini, F.C. (2007) Dissecting the Salmonella response to copper. Microbiology 153: 2989-2997.

Ewing, B., Hillier, L., Wendl, M.C., and Green, P. (1998) Base-calling of automated sequencer traces using phred. I. Accuracy assessment. Genome Res 8: 175-185. 
Flannagan, R.S., Cosio, G., and Grinstein, S. (2009) Antimicrobial mechanisms of phagocytes and bacterial evasion strategies. Nat Rev Microbiol 7: 355-366.

German, N., Doyscher, D., and Rensing, C. (2013) Bacterial killing in macrophages and amoeba: do they all use a brass dagger? Future Microbiol 8: 1257-1264.

Gonzalez, M., Romestand, B., Fievet, J., Huvet, A., Lebart, M.C., Gueguen, Y., and Bachere, E. (2005) Evidence in oyster of a plasma extracellular superoxide dismutase which binds LPS. Biochem Biophys Res Commun 338: 1089-1097.

Hernandez-Montes, G., Arguello, J.M., and Valderrama, B. (2012) Evolution and diversity of periplasmic proteins involved in copper homeostasis in gamma proteobacteria. BMC Microbiol 12: 249.

Hodgkinson, V., and Petris, M.J. (2012) Copper homeostasis at the host-pathogen interface. J Biol Chem 287: 13549- 13555.

Hood, M.I., and Skaar, E.P. (2012) Nutritional immunity: transition metals at the pathogen-host interface. Nat Rev Microbiol 10: 525-537.

Kang, I.H., Kim, J.S., and Lee, J.K. (2007) The virulence of Vibrio vulnificus is affected by the cellular level of superoxide dismutase activity. J Microbiol Biotechnol 17: 1399-1402.

Kim, J.S., Sung, M.H., Kho, D.H., and Lee, J.K. (2005) Induction of manganese-containing superoxide dismutase is required for acid tolerance in Vibrio vulnificus. J Bacteriol 187: 5984-5995.

Kremer, N., Schwartzman, J., Augustin, R., Zhou, L., Ruby, E.G., Hourdez, S., and McFall-Ngai, M.J. (2014) The dual nature of haemocyanin in the establishment and persistence of the squid-vibrio symbiosis. Proc Biol Sci 281: 20140504.

Le Roux, F., Binesse, J., Saulnier, D., and Mazel, D. (2007) Construction of a Vibrio splendidus mutant lacking the metalloprotease gene vsm by use of a novel counterselectable suicide vector. Appl Environ Microbiol 73: 777-784.

Le Roux, F., Davis, B.M., and Waldor, M.K. (2011) Conserved small RNAs govern replication and incompatibility of a diverse new plasmid family from marine bacteria. Nucleic Acids Res 39: 10041013.

Lemire, A., Goudenege, D., Versigny, T., Petton, B., Calteau, A., Labreuche, Y., and Le Roux, F. (2014) Populations, not clones, are the unit of vibrio pathogenesis in naturally infected oysters. ISME J 9: 1523-1531.

Li, H., Handsaker, B., Wysoker, A., Fennell, T., Ruan, J., Homer, N., et al. (2009) The Sequence Alignment/Map format and SAMtools. Bioinformatics 25: 2078-2079.

Luo, L., Ke, C., Guo, X., Shi, B., and Huang, M. (2014) Metal accumulation and differentially expressed proteins in gill of oyster (Crassostrea hongkongensis) exposed to long-term heavy metalcontaminated estuary. Fish Shellfish Immunol 38: 318-329.

Ma, A.T., McAuley, S., Pukatzki, S., and Mekalanos, J.J. (2009) Translocation of a Vibrio cholerae type VI secretion effector requires bacterial endocytosis by host cells. Cell Host Microbe 5: 234-243. 
Neyrolles, O., Wolschendorf, F., Mitra, A., and Niederweis, M. (2015) Mycobacteria, metals, and the macrophage. Immunol Rev 264: 249-263.

Niederhoffer, E.C., Naranjo, C.M., Bradley, K.L., and Fee, J.A. (1990) Control of Escherichia coli superoxide dismutase (sodA and $\operatorname{sod} B$ ) genes by the ferric uptake regulation (fur) locus. $J$ Bacteriol 172: 1930-1938.

Ning, Z., Cox, A.J., and Mullikin, J.C. (2001) SSAHA: a fast search method for large DNA databases. Genome Res 11: 1725-1729.

Pfaffl, M.W. (2001) A new mathematical model for relative quantification in real-time RT-PCR. Nucleic Acids Res 29: e45.

Poirier, A.C., Schmitt, P., Rosa, R.D., Vanhove, A.S., Kieffer-Jaquinod, S., Rubio, T.P., et al. (2014) Antimicrobial histones and DNA traps in invertebrate immunity: evidences in Crassostrea gigas. J Biol Chem 289: 24821- 24831.

Raimunda, D., Gonzalez-Guerrero, M., Leeber, B.W., 3rd, and Arguello, J.M. (2011) The transport mechanism of bacterial Cu+-ATPases: distinct efflux rates adapted to different function. Biometals 24: 467-475.

Ritchie, J.M., Rui, H., Zhou, X., lida, T., Kodoma, T., Ito, S., et al. (2012) Inflammation and disintegration of intestinal villi in an experimental model for Vibrio parahaemolyticusinduced diarrhea. PLoS Pathog 8: e1002593.

Rosenberg, E., and Falkovitz, L. (2004) The Vibrio shiloi/ Oculina patagonica model system of coral bleaching. Annu Rev Microbiol 58: 143-159.

Rowland, J.L., and Niederweis, M. (2012) Resistance mechanisms of Mycobacterium tuberculosis against phagosomal copper overload. Tuberculosis (Edinb) 92: 202-210.

Saulnier, D., Avarre, J.C., Le Moullac, G., Ansquer, D., Levy, P., and Vonau, V. (2000) Rapid and sensitive PCR detection of Vibrio penaeicida, the putative etiological agent of syndrome 93 in New Caledonia. Dis Aquat Organ 40: 109- 115.

Smith, T.F., and Waterman, M.S. (1981) Identification of common molecular subsequences. J Mol Biol 147: 195- 197.

Soldati, T., and Neyrolles, O. (2012) Mycobacteria and the intraphagosomal environment: take it with a pinch of salt(s). Traffic 13: 1042-1052.

de Souza Santos, M., and Orth, K. (2014) Intracellular Vibrio parahaemolyticus escapes the vacuole and establishes a replicative niche in the cytosol of epithelial cells. MBio 5: e01506-e01514.

Terwilliger, N., and Dumler, K. (2001) Ontogeny of decapod crustacean hemocyanin: effects of temperature and nutrition. J Exp Biol 204: 1013-1020.

Thompson, F.L., Thompson, C.C., and Swings, J. (2003) Vibrio tasmaniensis sp. nov., isolated from Atlantic salmon (Salmo salar L.). Syst Appl Microbiol 26: 65-69.

Val, M.E., Skovgaard, O., Ducos-Galand, M., Bland, M.J., and Mazel, D. (2012) Genome engineering in Vibrio cholerae: a feasible approach to address biological issues. PLoS Genet 8: e1002472. 
Vallenet, D., Belda, E., Calteau, A., Cruveiller, S., Engelen, S., Lajus, A., et al. (2013) MicroScope - an integrated microbial resource for the curation and comparative analysis of genomic and metabolic data. Nucleic Acids Res 41: D636-D647.

Vanhove, A.S., Duperthuy, M., Charriere, G.M., Le Roux, F., Goudenege, D., Gourbal, B., et al. (2015) Outer membrane vesicles are vehicles for the delivery of Vibrio tasmaniensis virulence factors to oyster immune cells. Environ Microbiol 17: 1152-1165.

Vidal-Dupiol, J., Ladriere, O., Destoumieux-Garzon, D., Sautiere, P.E., Meistertzheim, A.L., Tambutte, E., et al. (2011) Innate immune responses of a scleractinian coral to vibriosis. J Biol Chem 286: 22688-22698.

Wagner, D., Maser, J., Lai, B., Cai, Z., Barry, C.E., 3rd, Honer Zu Bentrup, K., et al. (2005) Elemental analysis of Mycobacterium avium-, Mycobacterium tuberculosis-, and Mycobacterium smegmatis-containing phagosomes indicates pathogen-induced microenvironments within the host cell's endosomal system. J Immunol 174: 1491-1500.

White, C., Lee, J., Kambe, T., Fritsche, K., and Petris, M.J. (2009) A role for the ATP7A coppertransporting ATPase in macrophage bactericidal activity. J Biol Chem 284: 33949- 33956.

Zhang, L., Krachler, A.M., Broberg, C.A., Li, Y., Mirzaei, H., Gilpin, C.J., and Orth, K. (2012) Type III effector VopC mediates invasion for Vibrio species. Cell Rep 1: 453-460. 


\section{Supporting information}

Additional Supporting Information may be found in the online version of this article at the publisher's web-site:

Fig. S1. LGP32-induced hemocyte cytolysis and release of bacteria.

Fig. S2. qRT-PCR validation of RNAseq data. Fig. S3. PCR validation of gene deletions.

Fig. S4. Growth of LGP32 mutants in liquid growth medium. Fig. S5. Phagocytosis of LGP32 mutants by oyster hemocytes.

Fig. S6. Growth in hemocyte co-cultures (A) and cytotoxicity $(\mathrm{B}, \mathrm{C})$ of the $\triangle a h p C$ mutant and $\triangle a h p C$ $\triangle t s a$ double mutant. Fig. S7. Increased susceptibility to copper of $\triangle$ copA but not $\triangle c u s A B$ mutant.

Fig. S8. Growth in hemocyte co-cultures (A) and cytotoxicity (B) of the $\triangle$ cus $A B$ mutant.

Table S1. Differential expression of LGP32 transcripts from RNAseq data.

Table S2. Strains, plasmids and oligonucleotides. Table S3. Oligonucleotides for qRT-PCR. 
Fig. 1. Hemocyte phagocytosis and cytolysis support efficient replication of LGP32.

A. Phagocytosis-dependent growth of LGP32 in hemocyte co-cultures. In three independent experiments, hemocyte monolayers wereincubated at a MOI of 50:1 with LGP32 or the avirulent control LMG 20012 ${ }^{\top}$. In controls, vibrios were incubated in SSW in the absence of hemocytes. Growth was monitored by the fluorescence of the GFP-expressing bacteria. Values are presented \pm SEM ***P $P 0.001$ (two-way rANOVA).

B. LGP32-induced hemocyte cytolysis and extracellular release of bacteria. Monolayers of hemocytes infected at a MOI of 50:1 withGFP-expressing LGP32 or LMG20012 ${ }^{\top}$ were observed $1 \mathrm{~h}$ and $5 \mathrm{~h}$ after contact. Both strains were rapidly phagocytosed. Major hemocyte lysis and release of extracellular vibrios was observed after $5 \mathrm{~h}$ upon exposure to LGP32 but not LMG 20012 ${ }^{\top}$. Nuclei were stained with DAPI and actin cytoskeleton with phalloidin-TRIC. Scale bar: $5 \mu \mathrm{m}$.

c. Phagocytosis-dependent cytolysis of hemocytes. Hemocyte monolayers were incubated with LGP32 or LMG $20012^{\top}$ at a MOI of 50:1 for phagocytosis in the presence/absence of cytochalasin D. Hemocyte cytolysis was monitored by using cell impermeant Sytox green DNA dye. The percentage of hemocyte lysis was obtained by comparison with a Triton X100-incuded lysis (100\% lysed hemocytes). Values are presented \pm SEM. $* * P<0.01$ (RM-ANOVA).

A

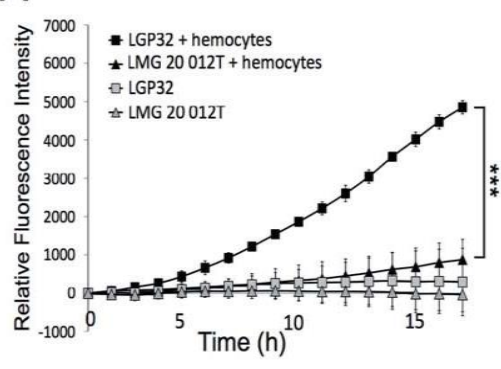

B
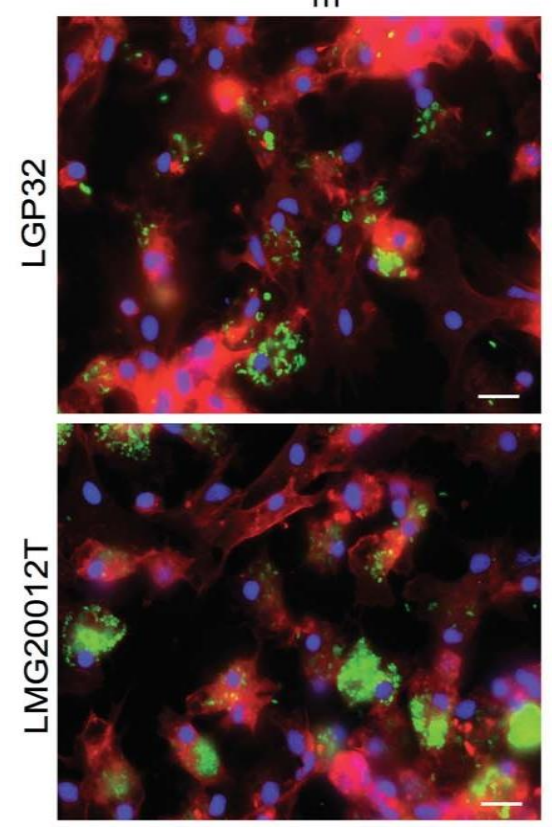

C

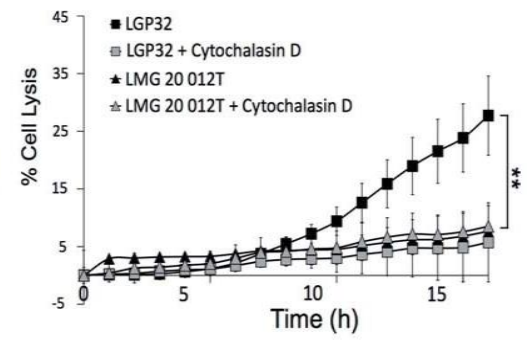

$5 \mathrm{~h}$
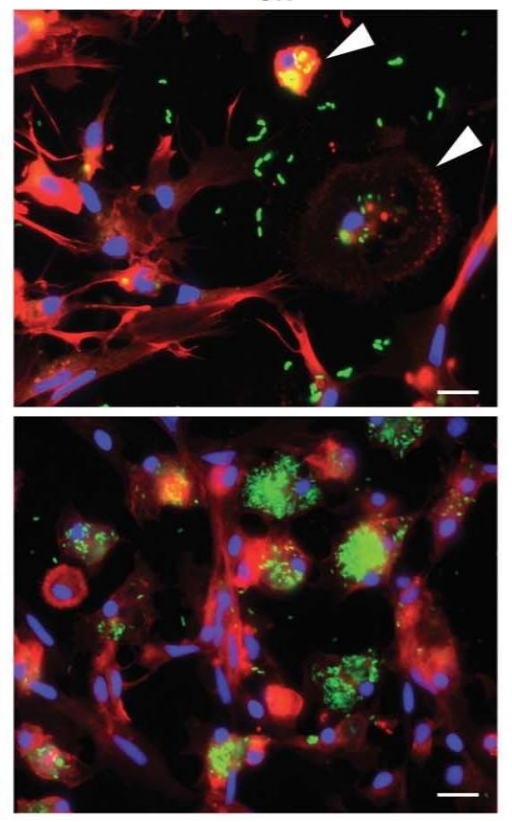


\section{Figure 2}

Time-course of LGP32 antioxidant and copper efflux gene expression monitored by qRT-PCR. Vibrio gene expression was analysed for every time point in three independent experiments. Conditions included vibrios in SSW (control), vibrios in oyster plasma (opsonization) and intracellular vibrios in oyster hemocytes. Three incubation times were tested (30 min, $1 \mathrm{~h}, 2 \mathrm{~h}$ ). Relative expression was calculated by normalization using three constitutively expressed genes VS_2913, VS_0852 and VS_II1055. Results were standardized relative to the control condition (vibrios in SSW). Data are the mean of gene expression in the three independent experiments \pm SEM. Data were analysed by twoway ANOVA and Tukey's post-test for multiple comparison, $* P<0.05, * * P<0.01, * * * P<0.001$.

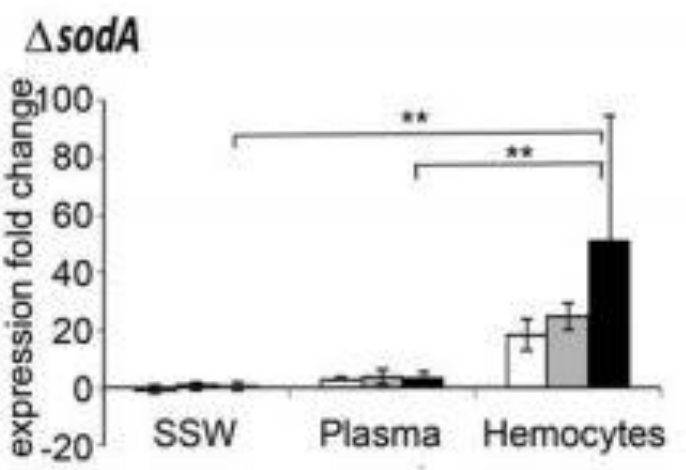

$\triangle a h p C$

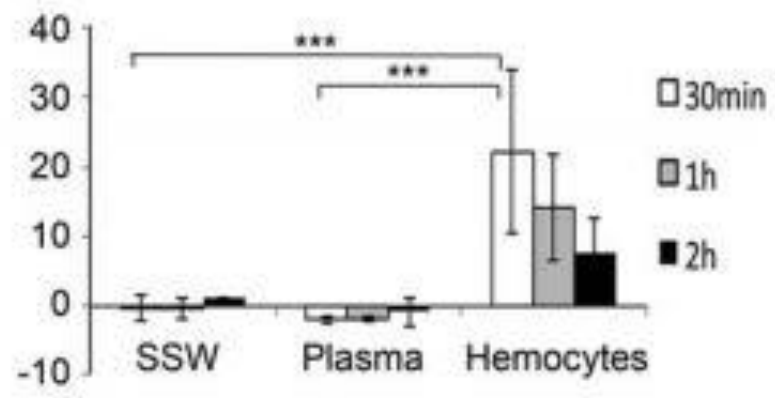

$\triangle \mathrm{copA}$

$\triangle$ CusB
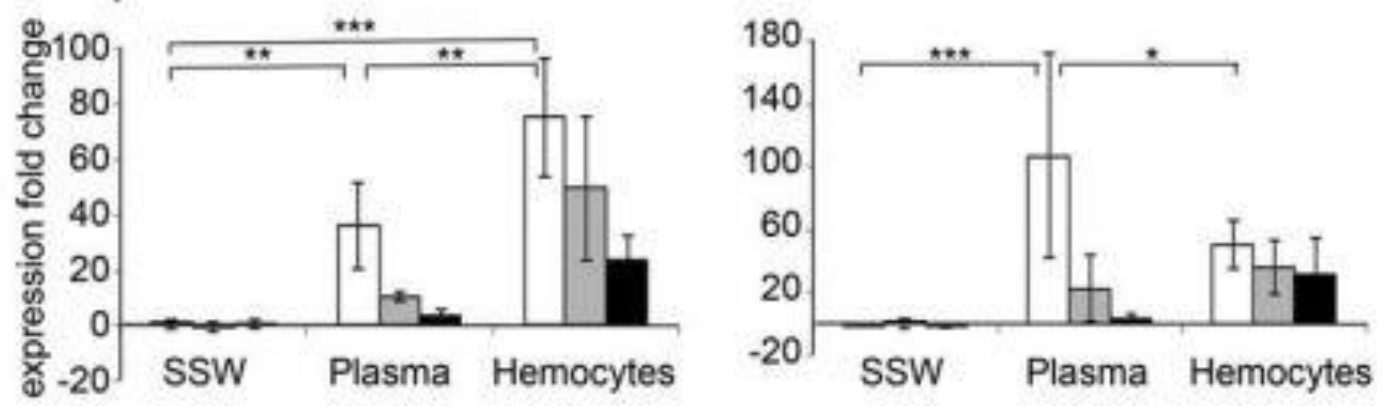


\section{Figure 3}

sodA is required for intracellular survival and cytotoxicity in phagocytes. In three independent experiments, hemocyte monolayers were incubated at a MOI of 50:1 with LMG 20012T (control), wild-type LGP32 or its $\Delta$ sodA isogenic mutants complemented or not with a low or high copy plasmid carrying sodA. A. Phagocytosis-dependent growth of LGP32 was monitored by the fluorescence of the GFP-expressing bacteria.

$* * * \mathrm{P}<0.001$ (RM-ANOVA). B. Cytotoxicity to hemocytes was monitored by the Sytox green assay. Values are presented \pm SEM.

$* * \mathrm{p}<0.01$

${ }^{*} \mathrm{P}<0.05$ (RM-ANOVA). C. Kaplan-Meier survival curves were generated from oysters injected with $4 \times 107$ cfu per animal of the wild-type LGP32 or the $\triangle$ sodA isogenic mutant. An injection of sterile seawater (SSW) was used as control. Groups of 45 oysters (15 per seawater tank) were monitored for 7 days after infection. One experiment representative of three independent experiments is shown.

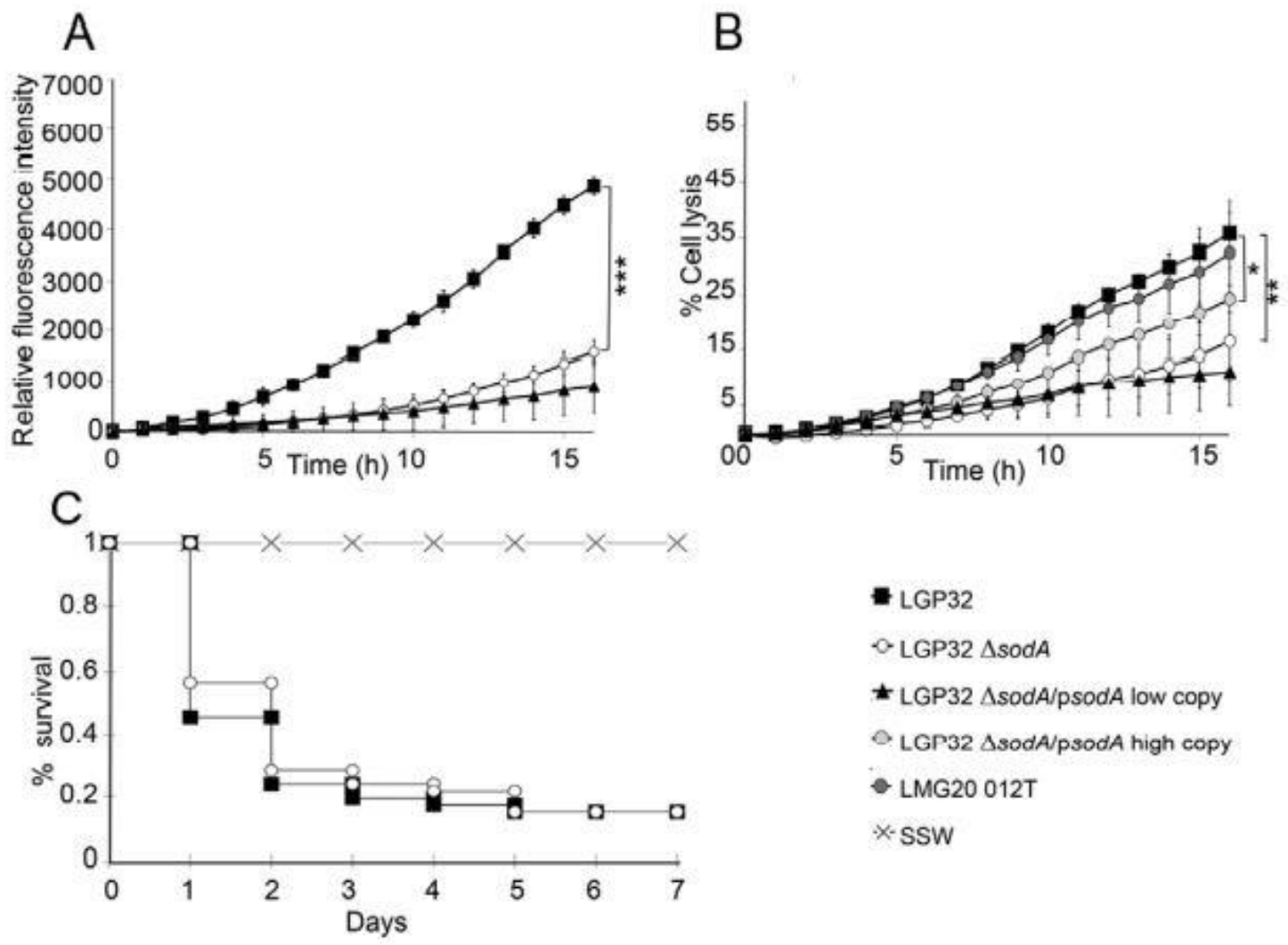




\section{Figure 4}

copA is required for intracellular survival, cytotoxicity in phagocytes, host colonization and virulence. Phagocytosis-dependent growth (A), cytotoxicity (B) and virulence (C) of bacteria were monitored. In (C), Kaplan-Meier survival curves were generated from oysters injected with $4 \times 107 \mathrm{cfu}$ per animal of the wildtype LGP32 or the $\triangle$ CopA isogenic mutant. One experiment representative of three independent experiments is shown. ${ }^{*} \mathrm{P}<0.05$ (log-rank test). Colonization (D) and competitive indexes (E) were tested by injecting juvenile oysters with fluorescent vibrios at $7 \times 107 \mathrm{cfu}$ per oyster and counting cfus from total oyster flesh either $2 \mathrm{~h}$ or $24 \mathrm{~h}$ after injection. Each dot represents one animal. For competitive indexes (E), the ratio between GFP-expressing $\triangle$ copA and mCherry-expressing LGP32 is shown in white boxes while the ratio between GFP-expressing LGP32 and mCherry-expressing LGP32 is shown in black boxes. For photographs of oyster hemolymph containing GFP-labelled vibrios $2 \mathrm{~h}$ after injection (F), oyster hemolymph was cytospun on a glass slide and stained with DAPI and TRITC-WGA. Arrowheads indicate LGP32 associated with cell debris.

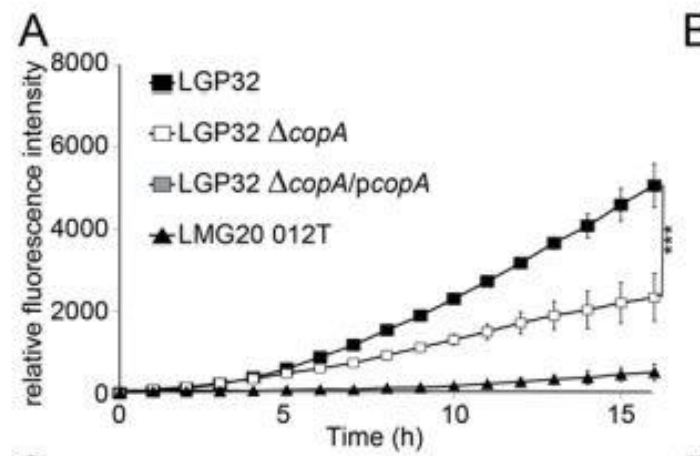

B

C
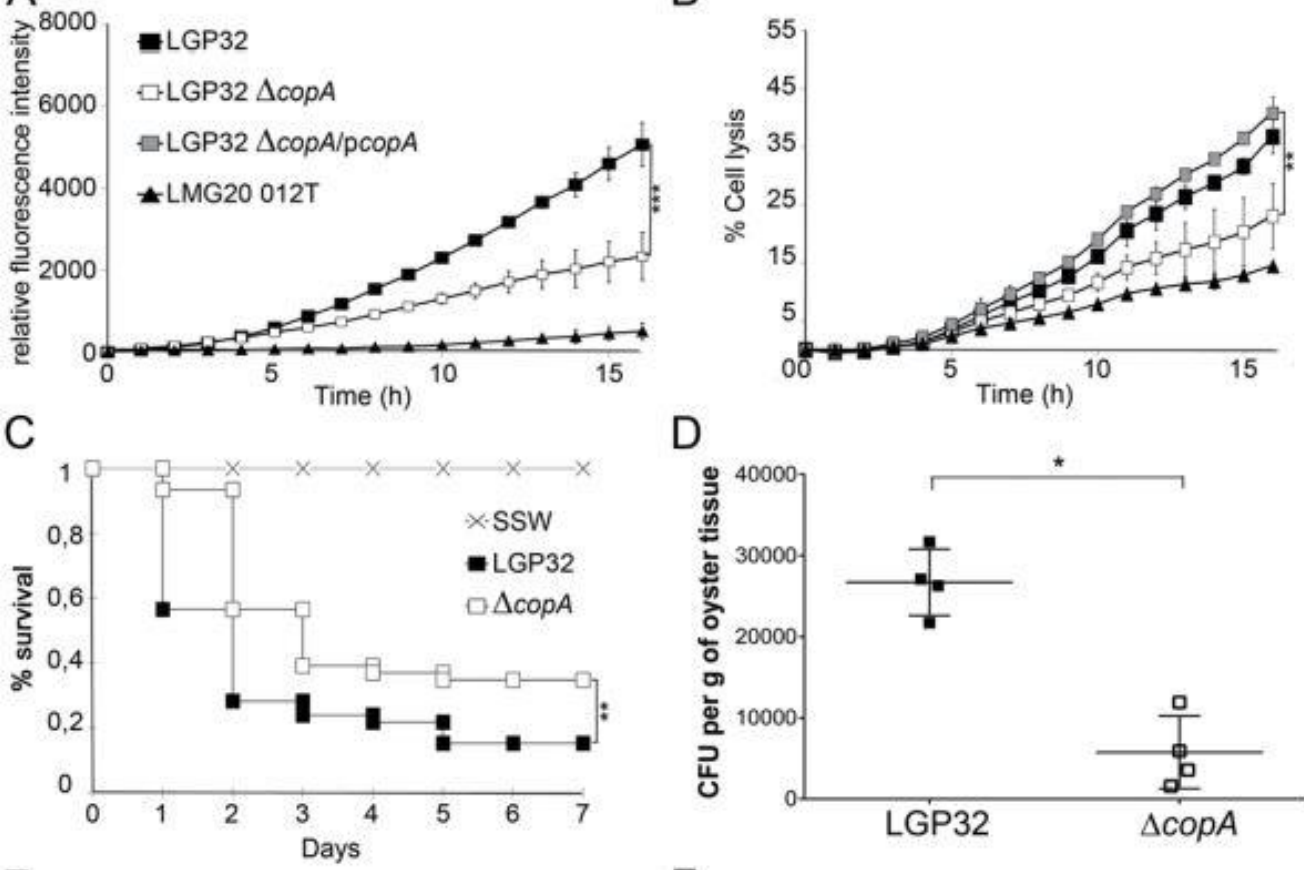

D

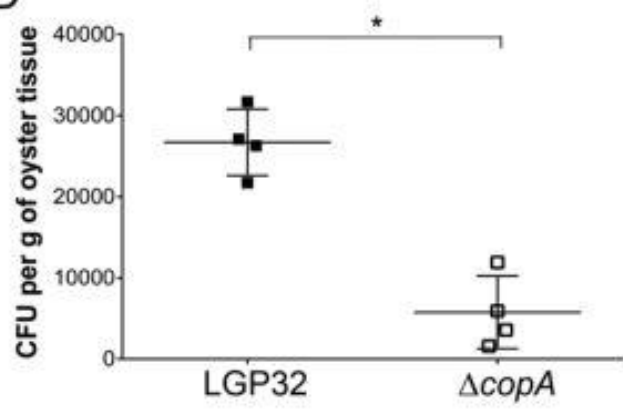

E

F

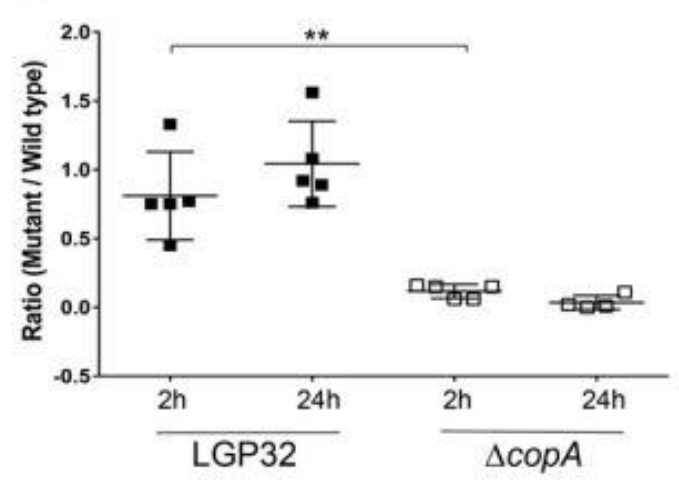

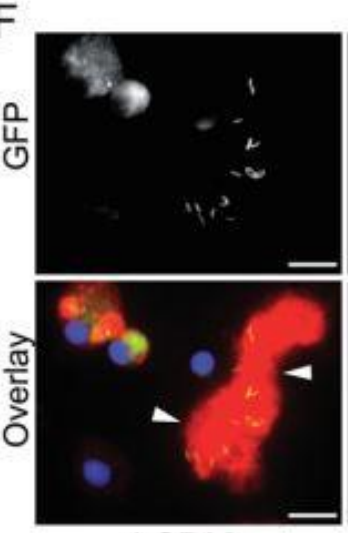

LGP32
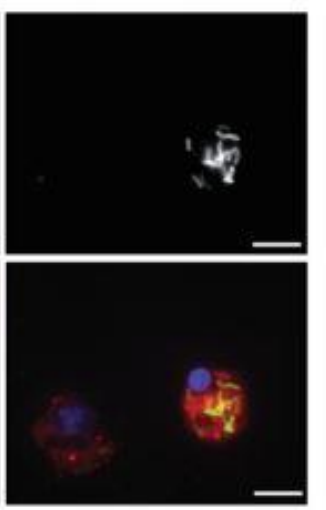

$\Delta c o p A$ 


\section{Table 1}

Functional categories referring to gene transcripts over/sub-represented in the intracellular condition

\begin{tabular}{lc} 
Functional category & Number of genes \\
\hline Protein synthesis & $105 / 12$ \\
Carbon compound utilization and transport & $83 / 31$ \\
Amino acid metabolism and transport & $93 / 19$ \\
Transport (others) & $22 / 41$ \\
Energy production and respiration & $34 / 28$ \\
Stress response & $25 / 32$ \\
Metal homeostasis & $39 / 9$ \\
Nucleoside and nucleotide metabolism & $30 / 5$ \\
Cofactor and small molecule carrier biogenesis & $23 / 8$ \\
DNA replication, recombination and repair & $21 / 9$ \\
Signalization & $8 / 21$ \\
LPS and capsule biogenesis & $21 / 7$ \\
Pilus biogenesis & $18 / 10$ \\
Glycolysis/gluconeogenesis/TCA cycle & $26 / 1$ \\
Virulence & $10 / 13$ \\
Envelope biogenesis & $15 / 6$ \\
Fatty acid and phospholipid metabolism & $12 / 9$ \\
Central intermediary metabolism & $13 / 3$ \\
Transcriptional regulation & $6 / 7$ \\
Chemotaxis & $9 / 3$ \\
Mobile genetic elements & $0 / 11$ \\
Protein and peptide degradation & $5 / 5$ \\
Cell division & $6 / 0$ \\
DNA metabolism & $2 / 3$ \\
Transcription & $3 / 1$ \\
Motility & $3 / 0$ \\
\hline & \\
\hline & \\
&
\end{tabular}




\section{Table 2}

List of the 34 transcripts enriched by more than 50 times in the intracellular condition.

\begin{tabular}{|c|c|c|}
\hline Label & Product & $\log 2$ fold change \\
\hline VS_II0905 & Putative endoribonuclease, translation inhibitor & 9.49 \\
\hline VS_II0514 & Copper efflux outer membrane protein, cusC & 9.2 \\
\hline VS_II0517 & Periplasmic copper-binding protein, cusF & 8.15 \\
\hline VS_II0904 & Aldehyde dehydrogenase & 7.65 \\
\hline VS_1283 & Conserved hypothetical protein & 7.26 \\
\hline VS_II0149 & Phospholipase & 6.96 \\
\hline VS_II1062 & Secreted metalloprotease PrtV/InhA prtV & 6.94 \\
\hline VS_2126 & Alkyl hydroperoxide reductase subunit C, ahpC & 6.9 \\
\hline VS_2127 & Alkyl hydroperoxide reductase subunit $F$, ahpF & 6.84 \\
\hline VS_II0515 & Copper efflux membrane fusion protein, cusB & 6.76 \\
\hline VS_1282 & Putative methylcobalamin:homocysteine methyltransferase, metE & 6.73 \\
\hline VS_2591 & Maltodextrin transport system permease protein, malC & 6.58 \\
\hline VS_1145 & $\begin{array}{l}\text { 5-methyltetrahydropteroyl } \\
\text { triglutamate-homocysteine methyltransferase }\end{array}$ & 6.55 \\
\hline VS_1068 & Outer membrane protein & 6.39 \\
\hline VIBSP2_misc_RNA_19 & IGR VS_II0219-VS_II0220, vsr217 & 6.37 \\
\hline VS_2589 & Cytoplasmic membrane-associated tetrahaem c-type cytochrome, cymA & 6.33 \\
\hline VS_3121 & Phosphoribosylaminoimidazole carboxylase ATPase subunit, purK & 6.33 \\
\hline VS_0992 & Oligopeptide transport system permease protein oppC & 6.28 \\
\hline VS_2246 & Putative succinate dehydrogenase, flavoprotein subunit & 6.13 \\
\hline VS_1313 & Putative tricarboxylate transport, tctC & 6.12 \\
\hline VS_2244 & succinate dehydrogenase, $\operatorname{sdh} B$ & 6.06 \\
\hline VS_II0903 & Putative dipeptidase & 6 \\
\hline VS_1461 & Cytochrome c oxidase subunit, $c c o Q$ & 5.93 \\
\hline VS_2585 & Cyclomaltodextrin glucanotransferase precursor & 5.92 \\
\hline VS_0768 & Copper-exporting P-type ATPase A, copA & 5.87 \\
\hline VS_0175 & Cold shock protein, $\operatorname{csp} A$ & 5.84 \\
\hline VS_1967 & Anthranilate synthase beta subunit, trpD & 5.81 \\
\hline VS_2927 & Aspartate carbamoyltransferase, catalytic chain, pyrB & 5.72 \\
\hline VS_II0545 & Putative glycine betaine transporter, betT & 5.71 \\
\hline VS_2382 & D-methionine transport ATP-binding protein, metN & 5.7 \\
\hline VS_2241 & Succinyl-CoA synthetase beta chain, sucC & 5.7 \\
\hline vS 110516 & Copper efflux membrane component, cusA & 5.69 \\
\hline VS_2918 & Superoxide dismutase, sodA & 5.69 \\
\hline VS_2242 & Dihydrolipoyllysine-residue succinyltransferase & 5.66 \\
\hline
\end{tabular}

See Supporting Information Table S1 for extensive list of differentially represented transcripts. Genes characterized in the present study are in boldface. 